OPEN ACCESS

Edited by:

Jinrui Zhang,

Tianjin University, China

Reviewed by:

Pavithra Parthasarathy,

University of Macau, China

Zhiyong Liu,

Southeast University, China

*Correspondence.

Muhan Wang

hldwmh@gmail.com

Specialty section

This article was submitted to

Structural Materials,

a section of the journal

Frontiers in Materials

Received: 18 January 2020 Accepted: 05 March 2020 Published: 23 June 2020

Citation:

Li Z, Zhang J and Wang M (2020) Structure, Reactivity, and Mechanical Properties of Sustainable Geopolymer Material: A Reactive Molecular

Dynamics Study. Front. Mater. 7:69.

doi: 10.3389/fmats.2020.00069

\section{Structure, Reactivity, and Mechanical Properties of Sustainable Geopolymer Material: A Reactive Molecular Dynamics Study}

\author{
Zhipeng Li ${ }^{1,2}$, Jinglin Zhang ${ }^{3}$ and Muhan Wang ${ }^{4 *}$ \\ ${ }^{1}$ School of Transportation and Logistics Engineering, Shandong Jiaotong University, Jinan, China, ${ }^{2}$ School of Civil \\ Engineering, Shandong Jiaotong University, Jinan, China, ${ }^{3}$ Collaborative Innovation Center of Engineering Construction \\ and Safety in Shandong Blue Economic Zone, Qingdao, China, ${ }^{4}$ School of Materials Science and Engineering, China \\ University of Petroleum, Qingdao, China
}

Sodium aluminosilicate hydrate (NASH) gel, the primary binding phase in geopolymer, determines the mechanical properties and durability of environment-friendly construction materials. In this work, the models of $\mathrm{NASH}$ gel were obtained through a two-step procedure: the temperature quenching method and Grand Canonical Monte Carlo water adsorption. The reactive force field (ReaxFF) molecular dynamics were utilized to investigate the structure, reactivity, and mechanical performance of the NASH gel with $\mathrm{Na} / \mathrm{Al}$ ratio ranging from 1 to 3 . Q species, the connectivity factor, shows that the increase of sodium content in NASH gel leads to depolymerization of the aluminosilicate network and more non-bridging oxygen (NBO) atoms. The adsorbed water molecules dissociate near the NBO with high reactivity in defective aluminosilicate structure. The newly produced hydroxyls associate with the aluminate species, contributing to the formation of the pentahedron local structure. The sodium ions distributed in the cavity of the aluminosilicate skeleton have around 47 nearest neighbors. Furthermore, with an increase in sodium, the molecular structure of the aluminosilicate skeleton is transformed from an integrity network to partially destroyed branch structures, which gradually decrease the stiffness and cohesive force of NASH gel, characterized by the uniaxial tensile testing. During the large tensile deformation process, the ReaxFF MD correlates the mechanical response with the chemical reaction pathway. The aluminosilicate skeleton is stretched broken to resist the tensile loading and the hydrolytic reaction of water molecules near the stretched $\mathrm{Si}-\mathrm{O}$ and $\mathrm{Al}-\mathrm{O}$ bond further accelerates the degradation of NASH gel. Hopefully, this work can shed light on the material design for a high performance of sustainable geopolymer at the nanoscale.

Keywords: molecular dynamics, geopolymer, sodium aluminosilicate hydrate, mechanical properties, structure

\section{INTRODUCTION}

Ordinary Portland cement (OPC) is ubiquitously utilized as the essential construction and building material worldwide ( $\mathrm{Li}, 2011$ ). Cement demand is estimated to increase from around $3.5 \mathrm{Gt}$ in 2015 to nearly 4.4 Gt per year by 2050 (Luukkonen et al., 2018). The manufacturing of OPC is accompanied with $\mathrm{CO}_{2}$ emissions such as the calcination of limestones at $1,450^{\circ} \mathrm{C}$ and the 
energy consumed by the cement plant itself, which is supplied by coal combustion (Damtoft et al., 2008). In 2016, the production of OPC contributed to around $1.45 \mathrm{Gt} \mathrm{CO}_{2}$, occupying approximately $8 \%$ of the global $\mathrm{CO}_{2}$ release (Andrew, 2018). Even though great efforts have made to improve energy efficiency, the clean production of cement remains a difficult issue to solve, especially considering the increasing cement demand and the inevitable $\mathrm{CO}_{2}$ emission reactions from cement production. Consequently, to reduce the carbon footprint, it is necessary to develop environment-friendly construction material to serve as an alternative and supplementary binder for OPC. Geopolymer, one type of alkali activated aluminosilicate cement, is used primarily as an environmentally beneficial alternative to OPC (Davidovits, 1991; Duxson et al., 2007a). Geopolymers use industrial byproducts as precursors, and therefore result in dramatically less $\mathrm{CO}_{2}$ emissions per ton of concrete produced (Duxson et al., 2007a). The industrial byproducts utilized in geopolymer synthesis include fly ash and slag, which when combined with alkaline activators react to form a hardened binder possessing performance characteristics comparable to traditional Portland cement (Davidovits, 1982; Palomo et al., 1999; Van Jaarsveld et al., 2002; Bakharev, 2005). It is synthesized by dissolution of $\mathrm{Al}$ and $\mathrm{Si}$ in alkali medium, transportation, and polycondensation, forming a three-dimensional network structure. Due to their inorganic three-dimensional network structure, geopolymers show high efficiency of fireproofing, excellent thermal stability, and superior mechanical properties as compared with traditional OPC (Palomo and Glasser, 1992; $\mathrm{Xu}$ and Van Deventer, 2000; Barbosa and MacKenzie, 2003; Kriven et al., 2003). Geopolymers have therefore received great growing in recent years in the field of cleaner production of construction materials.

Sodium aluminosilicate hydrate (NASH) gel is a primary binding phase in geopolymers. According to most of the papers published so far (White et al., 2012; Parthasarathy et al., 2017), the mechanical properties, mass transport, ion exchange, and other physicochemical properties of NASH gels are controlled by the chemical composition and nanostructure, which have drawn attention from researchers in related fields. In order to determine the coordination state of aluminum and oxygen, and to explain the abnormal changes of physical properties from the perspective of structure, many experiments and simulations have been carried out (McKeown et al., 1984; Leonelli et al., 2001; Okuno et al., 2005; Sadat et al., 2016). Earlier spectroscopic studies on geopolymer paste show that the structure of NASH gel primarily consists of an alkali aluminosilicate hydrate gel framework (the alkali used commonly is $\mathrm{Na}$ ) formed by disordered interlinked aluminosilicate tetrahedrons. $\mathrm{Al}$ and $\mathrm{Si}$ are both present in tetrahedral coordination connected by bridging oxygen (BO), and the negative charge associated with $\mathrm{Al}$ substitution for $\mathrm{Si}$ is balanced by the alkali cations (Barbosa et al., 2000; Duxson et al., 2005, 2007a,b; Singh et al., 2005). Compared with the bonding between $\mathrm{Na}$ and $\mathrm{NBO}$, the interaction between charge compensating alkali cations $\left(\mathrm{Na}^{+}\right)$and $\left[\mathrm{AlO}_{4}\right]^{-}$units are more ionic and weaker (Uchino et al., 1993). The $\mathrm{Na} / \mathrm{Al}$ ratio in compositions indicates the change in internal structure. In the geopolymers with low sodium content, $\mathrm{Na}^{+}$is bound superficially to the $\left[\mathrm{AlO}_{4}\right]^{-}$. When the $\mathrm{Na} / \mathrm{Al}$ ratio is larger than $1, \mathrm{Na}^{+}$may break the $\mathrm{Si}-\mathrm{O}-\mathrm{Si}$ linkage, associating it with part of the silicon in the form of $\mathrm{SiO}-\left(\mathrm{Na}^{+}\right)-\mathrm{Si}^{-}$(Uchino et al., 1993). Using molecular dynamics, Xiang et al. (2013) studied the changes in the structure and mechanical properties of sodium aluminosilicate glass as a function of $\mathrm{Al} / \mathrm{Na}$ ratios, and the results were in good agreement with experimental data. Zhang M. et al. (2018) studied the local structure and dynamics of sodium in NASH gel, demonstrated the loose connection between sodium and aluminate tetrahedron, and modeled the dissociation process of sodium, which is so-called leaching. Meanwhile, the ion immobilizing ability of NASH gel was studied by molecular dynamics, providing a fundamental understanding of the immobilization mechanism of geopolymer materials (Hou et al., 2019b). An empirical force field molecular dynamics method was also employed to investigate the structure, dynamics, energetics, and mechanical properties of calcium silicate hydrate (C-S-H) (Hou et al., 2019a, 2015b; Wang et al., 2019). Furthermore, reactive molecular dynamics were used to simulate the polymerization process and the molecular structure of geopolymer gels, and evaluated the influence of the simulation temperature and $\mathrm{Si} / \mathrm{Al}$ ratio on the geopolymer (Zhang M. et al., 2018).

Typically, the properties of the materials subjected to loading will be greatly reduced largely due to the degradation of the chemical and physical structure. The aluminosilicate skeleton significantly influences the adsorption capability, reactivity, and hydrogen bond of the structural water molecules. The way of binding water in NASH gel is of particular importance, as it is closely related to strength and stiffness. In some cases, the internal damage of NASH gel is caused by the hydrolysis reaction of the silicate network, attacked by dissociated water molecules (Hou et al., 2014a, 2016a). Sadat et al. (2016) reported that exposure to water promotes the diffusion and dissociation of structural sodium, leading to destabilization of aluminate tetrahedrons and underling mechanical failure of the local structure. However, minute quantities of water could stabilize the sodium in NASH gel, which was attributed to the hydrolysis associated with aluminate tetrahedron and the formation of $\mathrm{Na}-\mathrm{OH}$ (Zhang $\mathrm{Y}$. et al., 2018). The attack of water molecules on chemical bonds promoted bond breaking in the loading test (Hou et al., 2014a; Zhang Y. et al., 2018). In addition, some studies have focused on the effects of chemical compositions (Hou et al., 2015a, 2016b, 2015c). To the best of our knowledge, the mechanical properties and weakening mechanisms have not been fully understood and the case of coupling with hydrolysis and depolymerization, in particular, has not been studied yet.

In this study, NASH gel with different compositions of the $\mathrm{Na} / \mathrm{Al}$ ratio were characterized by molecular dynamics using a reactive force field (ReaxFF), which can perform a physical and chemical process in hydration, aiming to understand the structural role of sodium as a function of the chemical composition. The structural, mechanical, and chemical properties of NASH gel with different $\mathrm{Na} / \mathrm{Al}$ ratios have been investigated. The influences of an existent form of water within NASH gel were also analyzed to obtain a better understanding of their behavior. The obtained results highlight that NASH gel 
is weakened by the breakage of aluminosilicate chains and the penetration of water molecules, and show the mechanism of influence on its properties.

\section{MATERIALS AND METHODS}

\section{Reactive Force Field}

The ReaxFF, developed by van Duin et al. (2001), was used to simulate the chemical reaction between sodium aluminosilicate glass and water molecules for both atomic structure construction and uniaxial tensile testing. The ReaxFF provides an advanced description of the interaction between water and NASH surface. In addition, the ReaxFF has been widely used in silica glass (Hou et al., 2014a), C-S-H gel (Hou et al., 2015c), ordered crystal, and disordered glass (Hou et al., 2016b), discussing their structure evolution and tensile behavior under water penetration. The short-range interactions for the ReaxFF are determined by bond length-bond order scheme so that the bonds can be broken and formed with the potential energy transforming into a smooth state (Brenner et al., 2002). On the contrary, the long-range Coulombic interactions are determined by a seventh-order taper function, with an outer cutoff radius of $10 \AA$. The parameters of the force field for $\mathrm{Na}, \mathrm{Si}, \mathrm{Al}, \mathrm{O}$, and $\mathrm{H}$ can be obtained directly from previously published reference data (Cygan et al., 2004).

\section{NASH Models With Different $\mathrm{Na} / \mathrm{Al}$ Ratios}

The LAMMPS package was used to construct three NASH gel models with $\mathrm{Na} / \mathrm{Al}$ ratios of 1,2 , and 3 via two steps, respectively. First, a temperature quenching process was performed to build the NAS glass model. The water molecules were then inserted into the NAS glass model to obtain the NASH gel model. In order to obtain initial configuration with different $\mathrm{Na} / \mathrm{Al}$ ratios, four types of atoms ( $\mathrm{Na}, \mathrm{Si}, \mathrm{Al}$, and $\mathrm{O}$ ) were added in a cubic box with a side length of $20 \AA$ to generate random coordinates. The density was adjusted to a typical value (see Table 1; Sadat et al., 2016). A time step of 0.1 fs was used for the simulation. The system was operated by a heating/cooling cycle process from 300 to $4,000 \mathrm{~K}$ under NPT ensemble at a rate of $10 \mathrm{~K} / \mathrm{ps}$, then the system was cooled from 4,000 to $300 \mathrm{~K}$ at the same rate. Finally, the system was further equilibrated at NVT ensemble with the temperature maintained at $300 \mathrm{~K}$ for $300 \mathrm{ps}$. The simulated equilibrium structure of the aluminosilicate chain with different $\mathrm{Na} / \mathrm{Al}$ ratios are shown in Figure $\mathbf{1}$.

The Grand Canonical Monte Carlo (GCMC) method was utilized to adsorb water molecules into the NAS structure to obtain a NASH gel model (Bonnaud et al., 2012). The simulation process is analogous to the water adsorption in a microscopic porous structure such as C-S-H and silica glass (Hou et al., 2014a, 2015c). A two million step simulation was performed for the system equilibrium, followed by one million steps for data analysis. Water molecules can be inserted, deleted, displaced, and rotated in the constant volume system. After GCMC simulation, the NASH gel model saturated with water molecules will be obtained. The aluminosilicate skeletons with a $\mathrm{Na} / \mathrm{Al}$ ratio of 1 , 2, and 3 are shown in Figure 1. The composition of the NASH gel models is shown in Table 1.

\section{Uniaxial Tension Test}

A uniaxial tension test was utilized to detect the mechanical behavior of amorphous NASH gel. In order to reduce error and to ensure stability of the simulation system during stretching, the initial NASH models $(20 \times 20 \times 20 \AA)$ were expanded periodically $(40 \times 40 \times 40 \AA)$ and then used in a uniaxial tension test in the $\mathrm{X}$ direction. Moreover, there are 5,000 to 6,000 atoms in every supercell with a specific $\mathrm{Na} / \mathrm{Al}$ ratio. It should be noted that a large number of atoms in simulation models can provide stable statistical results, especially for the reliable failure modes. To explore the failure mechanism of the NASH gel, the stress-strain relation and the change of molecular structure during loading were investigated.

To obtain the stress-strain relations, the supercell structures were subjected to uniaxial tensile loadings through gradual elongation at a strain rate of $0.08 / \mathrm{ps}$. In the uniaxial tensile simulation process, NPT ensembles were defined for the system. When stretched along the $\mathrm{X}$ direction, the supercells were relaxed, coupled with zero external pressure in the $\mathrm{x}, \mathrm{y}$, and $\mathrm{z}$ dimensions at $300 \mathrm{~K}$ for $400 \mathrm{ps}$. Until the pressures reached equilibrium in three directions, the NASH gel would be elongated in the X direction. Furthermore, the pressure was zero in the $\mathrm{Y}$ and $\mathrm{Z}$ directions, respectively. Pressure evolution in the $\mathrm{X}$ direction was taken as the internal stress $\sigma_{\mathrm{xx}}$. By setting the pressure to 0 , which is perpendicular to the stretch direction, the normal direction can be relaxed toward the anisotropy without any restriction. The Poisson's ratio was considered in the setting, eliminating the artificial constraints of deformation.

\section{RESULTS AND DISCUSSION}

\section{Structure Properties}

After water adsorption, the molecular structures of the NASH gel were obtained. Water molecules penetrated into the cavity region of NAS glass and randomly distributed in the NASH gel. As shown in Figure 2, for gel with a Na/Al ratio of 1, two forms of the water molecules influencing the NAS glass can be found: chemical decomposition and physical adsorption. The water molecules adsorb and form physical bonds with NASH at first. Very small percentages of water molecules are decomposed to hydrogen and hydroxyl. The hydrogen forms a chemical bond with the oxygen of silicon-oxygen tetrahedron, and the hydroxyl forms a chemical bond with the aluminum. For chemical decomposition (see region I), a small number of water molecules (less than $7.2 \%$ ) break the aluminosilicate skeleton by occupying the BO site, and construct aluminum hydroxyl or silicate hydroxyl. In the case of physical adsorption water (see region II), the hydroxyl in water molecules point to the aluminosilicate skeleton to form a hydrogen bond with its oxygen atoms, and these water molecules, called physical adsorption water, makes up more than $92.8 \%$ of the total. From the molecular structure of the static state, physical adsorption is the main existing form for water molecules in NASH gel, and the proportion of decomposition is very low. This conclusion agrees with previously published works (Hou et al., 2014a; Zhang Y. et al., 2018). 
TABLE 1 | Compositions and densities of simulated NASH gel.

\begin{tabular}{|c|c|c|c|c|c|c|c|}
\hline $\mathrm{Na} / \mathrm{Al}$ ratio & $\mathrm{Na}_{2} \mathrm{O}$ (wt. \%) & $\mathrm{Al}_{2} \mathrm{O}_{3}$ (wt. \%) & $\mathrm{SiO}_{2}$ (wt. \%) & $\mathrm{H}_{2} \mathrm{O}$ (wt. \%) & $\begin{array}{l}\text { Total atoms in } \\
\text { simulation cell }\end{array}$ & $\begin{array}{l}\text { NAS density } \\
\left(\mathrm{g} / \mathrm{cm}^{3}\right)\end{array}$ & $\begin{array}{l}\text { NASH density } \\
\left(\mathrm{g} / \mathrm{cm}^{3}\right)\end{array}$ \\
\hline 1 & 11.00 & 18.10 & 64.37 & 6.53 & 682 & 2.41 & 2.57 \\
\hline 2 & 20.65 & 16.78 & 59.24 & 3.39 & 688 & 2.56 & 2.65 \\
\hline 3 & 28.19 & 15.46 & 54.57 & 1.77 & 710 & 2.70 & 2.74 \\
\hline
\end{tabular}

The three-dimensional network structure of the NASH gel with a $\mathrm{Na} / \mathrm{Al}$ ratio of 1 is shown in Figure 2, which is the most representative feature. In the structure, silicon and aluminum atoms are interconnected by $\mathrm{BO}$, and nearby sodium ions play a role in charge balance (Barbosa et al., 2000; Schmücker and MacKenzie, 2005). The coordination number (CN) of NASH gel, obtained using dynamic simulations, shows the local structure. In thermodynamic equilibrium state, as shown in Table 2, the

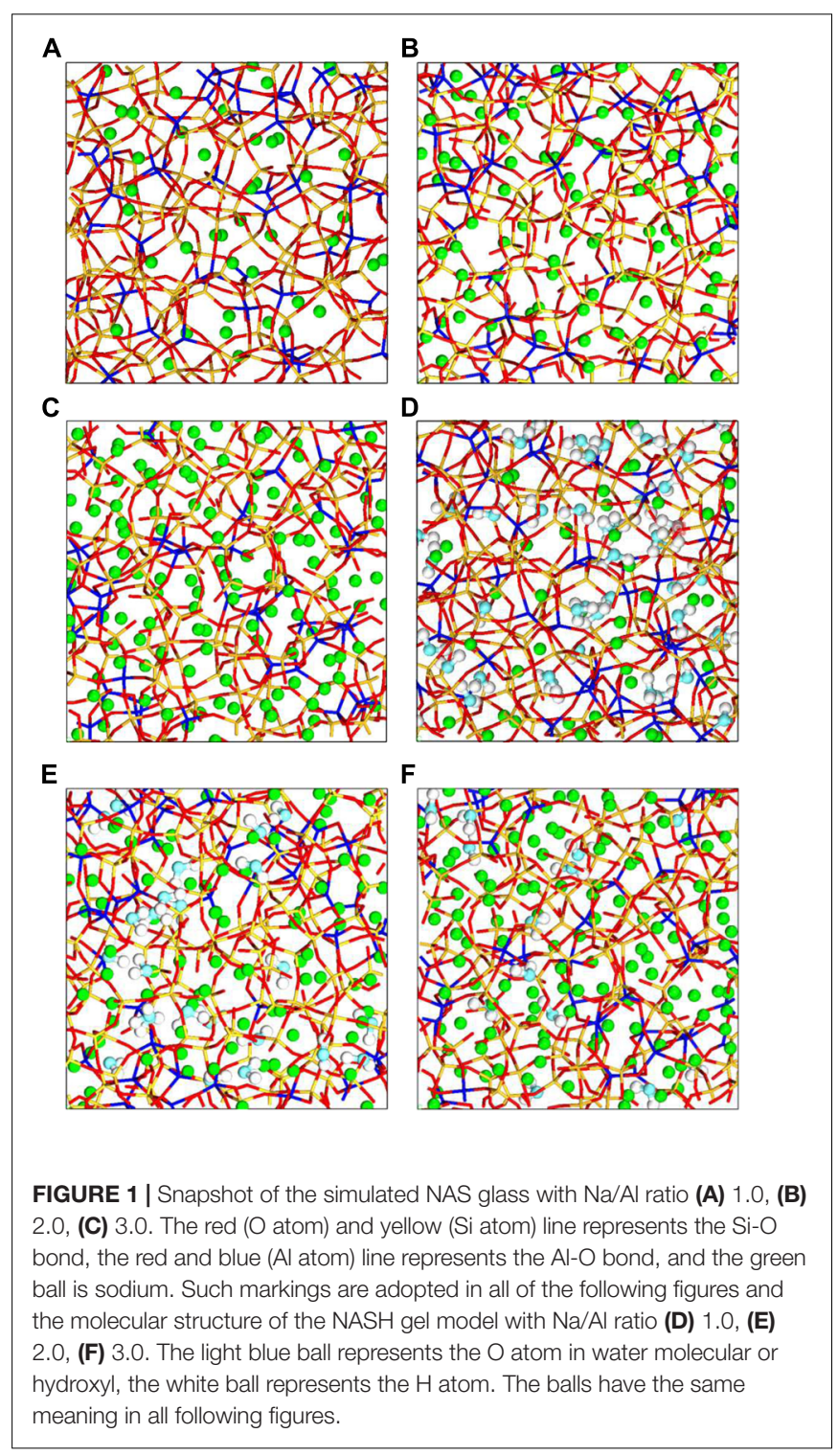

$\mathrm{CN}$ of all the silicon in the gel with different $\mathrm{Na} / \mathrm{Al}$ ratios is fourfold coordination, indicating that silicon in NASH gel exists in the form of tetrahedron. The aluminum coordination in the network structure is also predominantly tetrahedral $(\sim 95.57$, 94.14 , and $96.51 \%)$, and some aluminum ( 2.16, 5.84, and 3.49\%) with fivefold coordination, which is related to formation of Al$\mathrm{O}_{\mathrm{w}} \mathrm{H}_{\mathrm{w}}$. Sodium diffuses in the cavity of the Si-Al framework, and exists in the form of $\mathrm{Na}\left(\mathrm{H}_{2} \mathrm{O}\right)_{n}{ }^{+}$rather than $\mathrm{Na}^{+}$, implying a loose interaction between sodium and the neighboring $\mathrm{Si}^{-}$ $\mathrm{O}-\mathrm{Al}$ bond. Sodium is located at a vacant region among the skeleton, showing multiple coordination forms. The results of MD simulation match well with previous experimental results (Barbosa et al., 2000; Duxson et al., 2005; De Silva et al., 2007; Walkley et al., 2018).

In NASH gel, $\mathrm{Si}$ and $\mathrm{Al}$ are predominantly tetrahedral, which can also be revealed by the angle distribution of the O-Si-O, Si$\mathrm{O}-\mathrm{Si}$, and $\mathrm{O}-\mathrm{Al}-\mathrm{O}$ angle. As shown in Figures 3A,B, the angle distributions of $\mathrm{Si}-\mathrm{O}-\mathrm{Si}$ and $\mathrm{O}-\mathrm{Si}-\mathrm{O}$ are almost fully overlapped for different $\mathrm{Na} / \mathrm{Al}$ ratio gels, indicating that the tetrahedral $\mathrm{SiO}_{4}$ structure and the silicate skeleton is not sensitive to the $\mathrm{Na} / \mathrm{Al}$ ratio. The $\mathrm{O}-\mathrm{Si}-\mathrm{O}$ angles are mainly distributed between $90^{\circ}$ and $130^{\circ}$. The obvious peak located at around $110^{\circ}$, matches well with the experimental result of $109.7^{\circ}$ measured by neutron diffraction (Mozzi and Warren, 1969). The simulated Si-O-Si angle distribution of the NASH gel ranges from $110^{\circ}$ to $180^{\circ}$, and the average value is located at $144.0^{\circ}, 143.4^{\circ}$, and $142.7^{\circ}$,

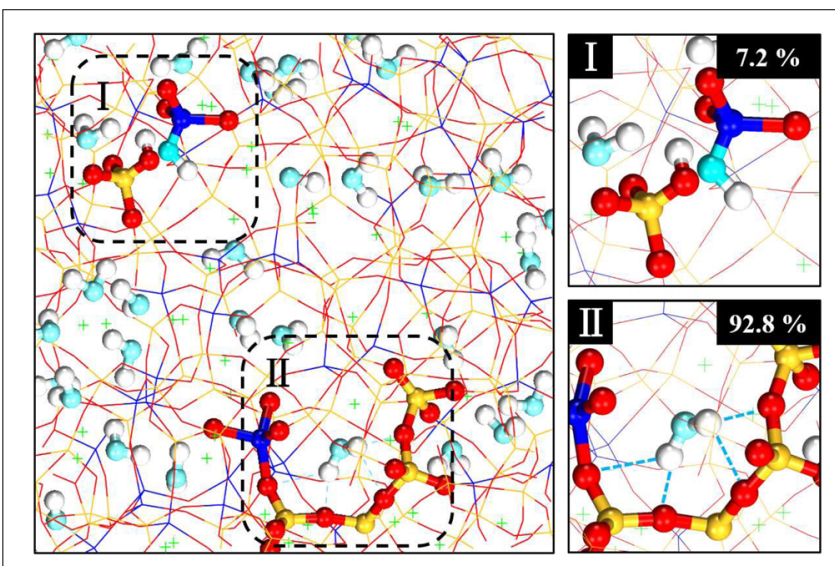

FIGURE 2 | Snapshot for the NASH gel with water penetration. The left-hand figure is the configuration of the NASH gel with a Na/Al ratio of 1. Region I and region II represent chemically dissociated water and physical adsorption water, respectively. Region I and region II are highlighted in the right-hand figures. The red ball is the $\mathrm{BO}$ atom in the aluminosilicate skeleton. The blue ball is the aluminum atom. The yellow ball is the silicon atom. 
TABLE 2 | Coordination number (CN) of NASH gel model with different $\mathrm{Na} / \mathrm{Al}$ ratios.

\begin{tabular}{lccccc}
\hline $\mathbf{N a}$ /Al ratio & $\mathbf{C N}(\boldsymbol{n})$ & $\mathbf{4}(\mathbf{\%})$ & $\mathbf{5}(\mathbf{\%})$ & $\mathbf{6}(\mathbf{\%})$ & $\mathbf{7}$ (\%) \\
\hline 1 & $\mathrm{Si}-\mathrm{O}_{\mathrm{n}}$ & 100 & - & - & - \\
& $\mathrm{Al}-\mathrm{O}_{\mathrm{n}}$ & 95.57 & 2.16 & - & - \\
& $\mathrm{Na}-\mathrm{O}_{\mathrm{n}}$ & 24.99 & 30.54 & 25.74 & 7.50 \\
2 & $\mathrm{Si}-\mathrm{O}_{\mathrm{n}}$ & 100 & - & - & - \\
& $\mathrm{Al}-\mathrm{O}_{\mathrm{n}}$ & 94.14 & 5.84 & - & - \\
& $\mathrm{Na}-\mathrm{O}_{\mathrm{n}}$ & 10.76 & 29.85 & 41.02 & 14.33 \\
& $\mathrm{Si}-\mathrm{O}_{\mathrm{n}}$ & 100 & - & - & - \\
& $\mathrm{Al}-\mathrm{O}_{\mathrm{n}}$ & 96.51 & 3.49 & - & - \\
& $\mathrm{Na}-\mathrm{O}_{\mathrm{n}}$ & 4.87 & 29.31 & 37.74 & 22.97 \\
\hline
\end{tabular}

respectively. The simulation results are in agreement with the experimental results given by nuclear magnetic resonance, and $\mathrm{X}$-ray diffractions are between $142^{\circ}$ and $151^{\circ}$ (Mauri et al., 2000). More significantly, the $\mathrm{Si}-\mathrm{O}-\mathrm{Si}$ angle peak value decreased slightly with the increase of the $\mathrm{Na} / \mathrm{Al}$ ratio due to the change of sodium ions. However, Figure $3 \mathrm{C}$ shows that the angle distributions of $\mathrm{O}-\mathrm{Al}-\mathrm{O}$ are far broader than that of $\mathrm{O}-\mathrm{Si}-\mathrm{O}$, and there are more obvious peaks located at different angles. It can be attributed to two possible factors: aluminum exists in multiple coordination configurations in the NASH gel, and the Al-O bond is relatively unstable in the aluminosilicate skeleton compared with the Si-O bond.

\section{Mechanical Properties Stress-Strain Relation for NASH Gel}

Given the constitutive stress-strain relation, the stress-strain curve can reflect the mechanical properties of NASH gel in the process of uniaxial tension testing. Due to the isotropic structure of NASH, in the directions X, Y, and Z, they have the same stressstrain curves. Figure 4 shows the constitutive relation between stress and strain with a strain rate of $0.08 / \mathrm{ps}$ along the $\mathrm{X}$ direction. Although the stress-strain curves have similar evolutionary
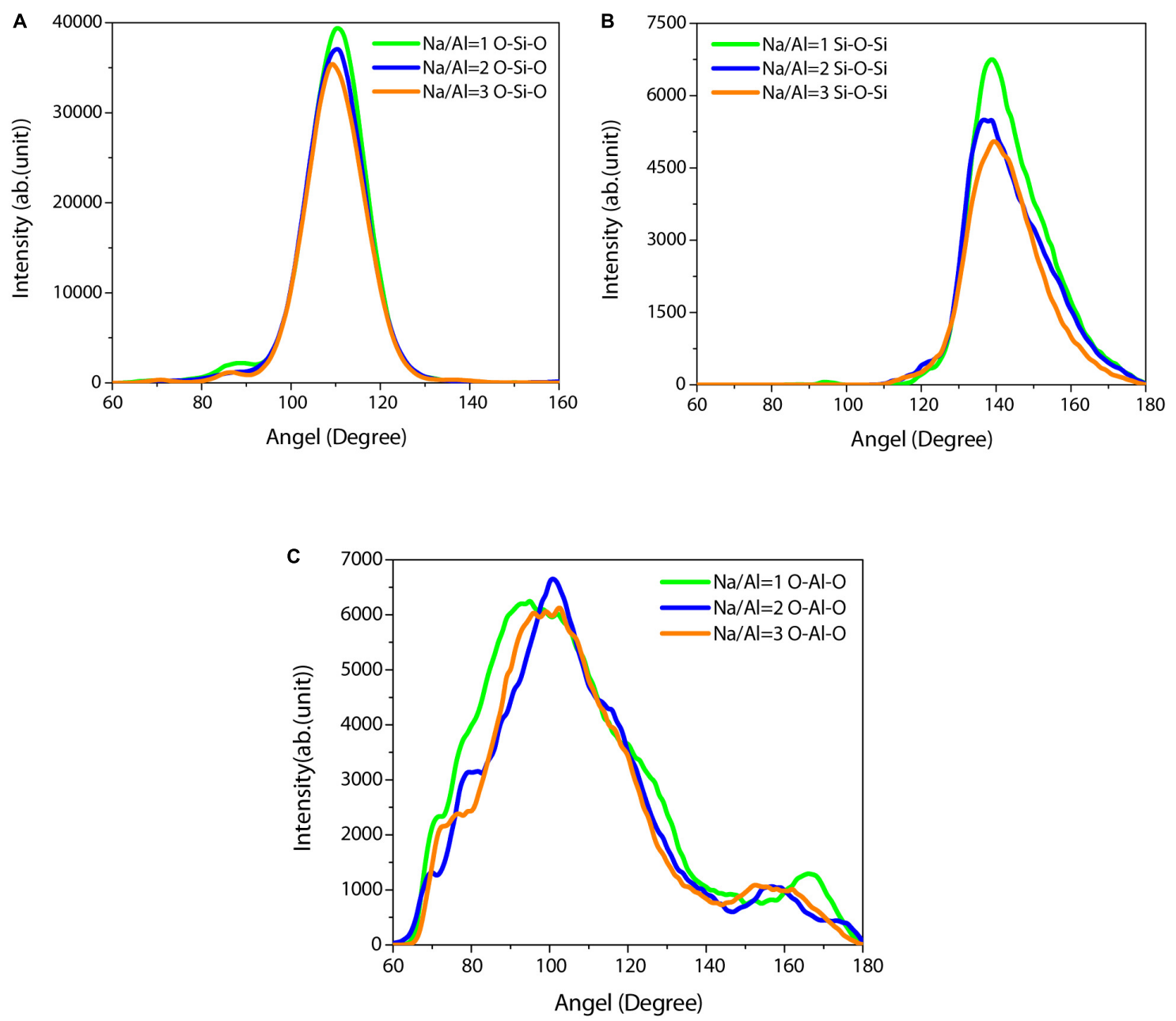

10

FIGURE 3 | (A) O-Si-O, (B) Si-O-Si, and (C) O-Al-O angle distribution of the NASH gel with a Na/Al ratio of 1, 2, and 3. 


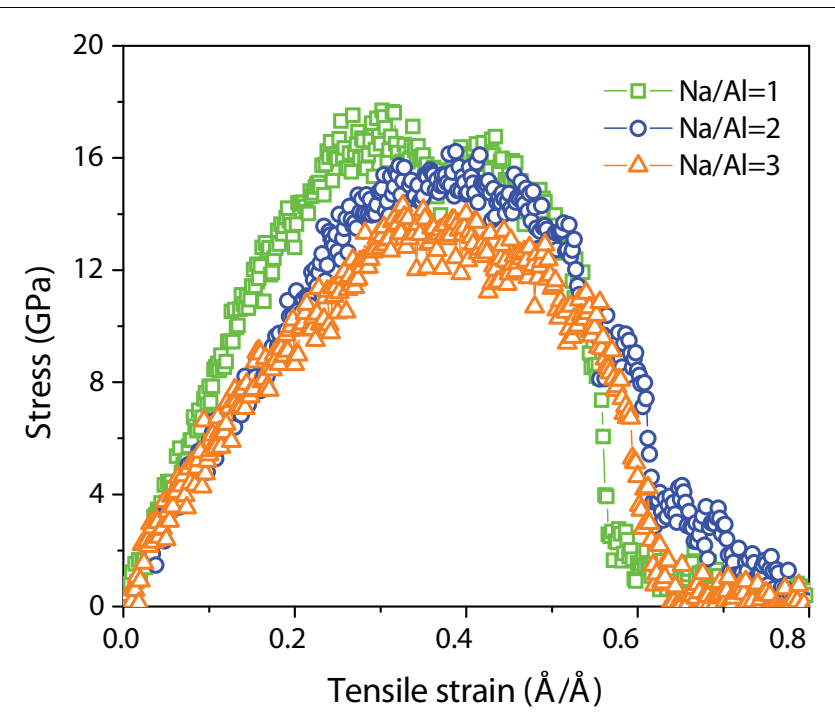

FIGURE 4 | Stress-strain relation for NASH gel with a ratio of 1, 2, and 3, stretched along the $X$ direction with a strain rate of $0.08 / p s$.

trends, the intrinsic strength and failure strain of the specimen with a different $\mathrm{Na} / \mathrm{Al}$ ratio is obviously different from others. The tensile strain, when the stress reaches the maximum value, is gradually decreased from $0.45 \AA / \AA$ to $0.3 \AA / \AA$. The NASH gel with a lower $\mathrm{Na} / \mathrm{Al}$ ratio is more easily stretched broken, and the yield strength of the NASH gel with a Na/Al ratio of 1,2 , and 3 is $17.7,16.2$, and $14.3 \mathrm{GPa}$, respectively. From the perspective of composition, the stress maximum value decreased as the $\mathrm{Na} / \mathrm{Al}$ ratio increased. The number of sodium ions beyond that required, compensated for the negatively charged [AlO4] ${ }^{-}$units. Excess sodium ions with a positive charge can then attack the $\mathrm{Si}$ O-Si and Si-O-Al bond (Irwin et al., 1988; Barbosa et al., 2000; Schmücker and MacKenzie, 2005), leading to aluminosilicate skeleton instability. It means that the increase of sodium content reduces the mechanical strength of the system. This result is consistent with the experimental result that the compressive strengths are decreased with increasing the $\mathrm{Na} / \mathrm{Al}$ ratios when the $\mathrm{Na} / \mathrm{Al}$ ratio is greater than 1 (Rowles and O'connor, 2003).

The stress-strain relations for different $\mathrm{Na} / \mathrm{Al}$ ratios show the detailed mechanical performance during the process of tensile loading. The whole process can be divided into several stages. Taking the $\mathrm{NASH}$ gel with a $\mathrm{Na} / \mathrm{Al}$ ratio of 1 as an example, the stress initially increases linearly in the elastic stage and subsequently slowly increases to a maximum value at a strain around $0.30 \AA / \AA$. After the stress varies very slowly with strain from 0.3 to $0.45 \AA / \AA$, there is a region with a dramatic drop in stress as the strain increases. Finally, the NASH gel was completely fractured at a strain of $0.8 \AA / \AA$, corresponding to zero stress. It is obvious that the NASH gel is more prone to yield deformation as the $\mathrm{Na} / \mathrm{Al}$ ratio increases. As the $\mathrm{Na} / \mathrm{Al}$ ratio increase from 1 to 3 in the NASH gel, the tensile strength of the gel greatly decreases from 17.69 to $14.30 \mathrm{GPa}$ accompanied by Young's modulus deduction from 71.84 to 47.46 GPa (see Table 3), and results in an obvious decrease of
TABLE 3 | Young's modulus of NASH gel models with different $\mathrm{Na} / \mathrm{Al}$ ratios.

\begin{tabular}{lccc}
\hline $\mathbf{N a} / \mathbf{A l}$ & $\mathbf{1}$ & $\mathbf{2}$ & $\mathbf{3}$ \\
\hline Young's modulus (GPa) & 71.84 & 50.16 & 47.46 \\
Tensile strength (GPa) & 17.69 & 16.22 & 14.30
\end{tabular}

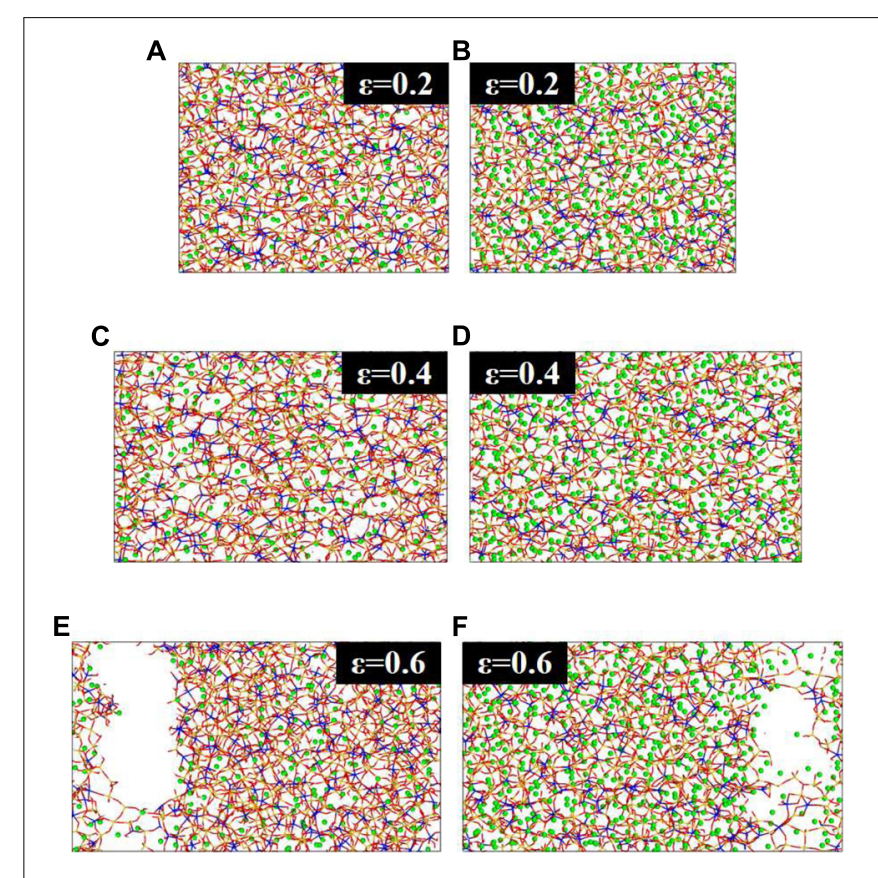

FIGURE 5 | Evolution of the structure during the tensile process with a $\mathrm{Na} / \mathrm{Al}$ ratio of 1 and 3 . From top to bottom, the strain state is $0.2(\mathbf{A}, \mathbf{B}), 0.4(\mathbf{C}, \mathbf{D})$, and 0.6 (E,F) $\AA / \AA$, respectively.

ultimate tensile strength of the NASH gel. For the specimens with different $\mathrm{Na} / \mathrm{Al}$ ratios, the difference in the mechanical properties can be explained by different molecular structures and reactivity mechanisms.

\section{Molecular Local Structure Evolution}

The evolution of the structure during the tensile process from a strain of $0.2 \AA / \AA$ to $0.6 \AA / \AA$ is shown in Figure 5, a preliminary qualitative illustration of the damage process in the NASH gel. The aluminosilicate skeleton is stretched broken to resist the tensile loading. In the elastic region, $\mathrm{Si}-\mathrm{O}$ and $\mathrm{Al}-\mathrm{O}$ bonds in the aluminosilicate skeleton, subjected to tensile loading, are elongated. The Si-O-Si and $\mathrm{Si}-\mathrm{O}-\mathrm{Al}$ angles are stretched to bear the strain in the NASH gel system. In the subsequent yield region, the $\mathrm{Si}-\mathrm{O}$ and $\mathrm{Al}-\mathrm{O}$ bonds break down gradually, causing morphology transformation. As shown in Figure 5, the shape of the aluminosilicate skeleton changes at the strain of $0.4 \AA / \AA$ due to the bond breakage and reconnection. Small cracks have been created during the tensile process, but the local structure rearrangement slows down its propagation (Hou et al., 2014b, 2015c). In the failure stage of strain states $0.4 \AA / \AA$ to $0.6 \AA / \AA$, the cracks created before continuing to grow and coalesce fast as strain increases in the area with the defective aluminosilicate skeleton, leading to the stress dropping rapidly (see Figures 4, 5). 

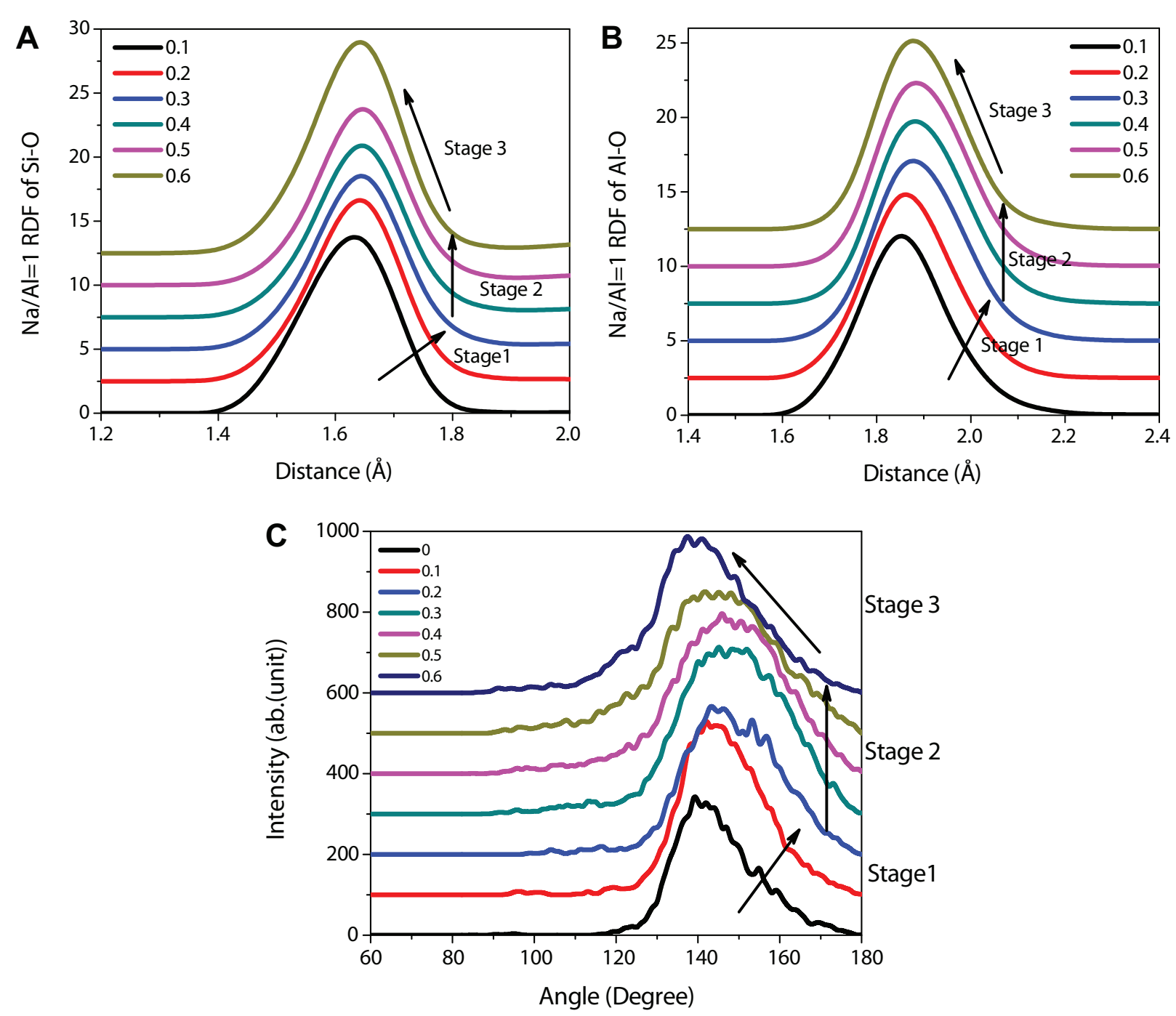

FIGURE 6 | Evolution of RDF for (A) Si-O, (B) Al-O stretched by loading with a rate of 0.08/ps, and (C) Si-O-Si angle distribution as a function of strain for the NASH gel with a $\mathrm{Na} / \mathrm{Al}$ ratio of 1 . Stage 1,2 , and 3 represent the elastic region, yield region, and failure region, respectively.

It should be noted that the increase of sodium ions at the end of the crack tips prevents the Si-O-Si and Si-O-Al bonds' reconnection, and further decreases the tensile properties of the gel structure. According to Table 2, the higher the $\mathrm{Na} / \mathrm{Al}$ ratio, the more $\mathrm{Na}-\mathrm{O}$ bonds and the less $\mathrm{Al}-\mathrm{O}$ bonds form. The $\mathrm{Na}$ and $\mathrm{Al}$ are competitive, therefore, we can conclude that the aluminosilicate skeleton is unstable after an increase in the ratio of $\mathrm{Na} / \mathrm{Al}$.

TABLE 4 | Q species, bridging oxygen (BO), and non-bridging oxygen (NBO) of the $\mathrm{NASH}$ gel model with different $\mathrm{Na} / \mathrm{Al}$ ratios.

\begin{tabular}{lccccc}
\hline Na/Al ratio & $\mathbf{Q}_{\mathbf{4}}(\%)$ & $\mathbf{Q}_{\mathbf{3}}(\%)$ & $\mathbf{Q}_{\mathbf{2}}(\%)$ & BO (\%) & NBO (\%) \\
\hline 1 & 81.22 & 5.09 & - & 97.13 & 2.87 \\
2 & 60.64 & 21.65 & 5.36 & 83.25 & 16.75 \\
3 & 51.25 & 26.88 & 10.63 & 76.92 & 23.08
\end{tabular}

For the purpose of investigating the morphology evolution quantitatively, the RDF, angle distribution, and Q species changes have been calculated to depict the structural variation of the aluminosilicate skeleton during the tensile process. The RDFs of $\mathrm{Si}-\mathrm{O}$ and $\mathrm{Al}-\mathrm{O}$ as a function of strain for the NASH gel with a $\mathrm{Na} / \mathrm{Al}$ ratio of 1 are shown in Figures $\mathbf{6 A}, \mathbf{B}$. Based on Figures $6 \mathbf{A}, \mathbf{B}$, the spectrums show similar peak emerging positions, indicating that the $\mathrm{Si}-\mathrm{O}$ or $\mathrm{Al}-\mathrm{O}$ were changed slightly during stretching. For the RDFs of Si-O, the peak positions of different strains are slightly different. In stage 1 (the elastic region), the $\mathrm{Si}-\mathrm{O}$ peaks shift toward a lager distance with an increasing strain, which means the elastic elongation of the Si-O bonds. In stage 2 (the yield region), the peak positions of $\mathrm{Si}-\mathrm{O}$ at different strains remain almost the same, implying that the continuous break and reconnection of a large number of $\mathrm{Si}-\mathrm{O}$ bonds causes rearrangement of aluminosilicate chains. This is consistent with the conclusion obtained above from the evolution 

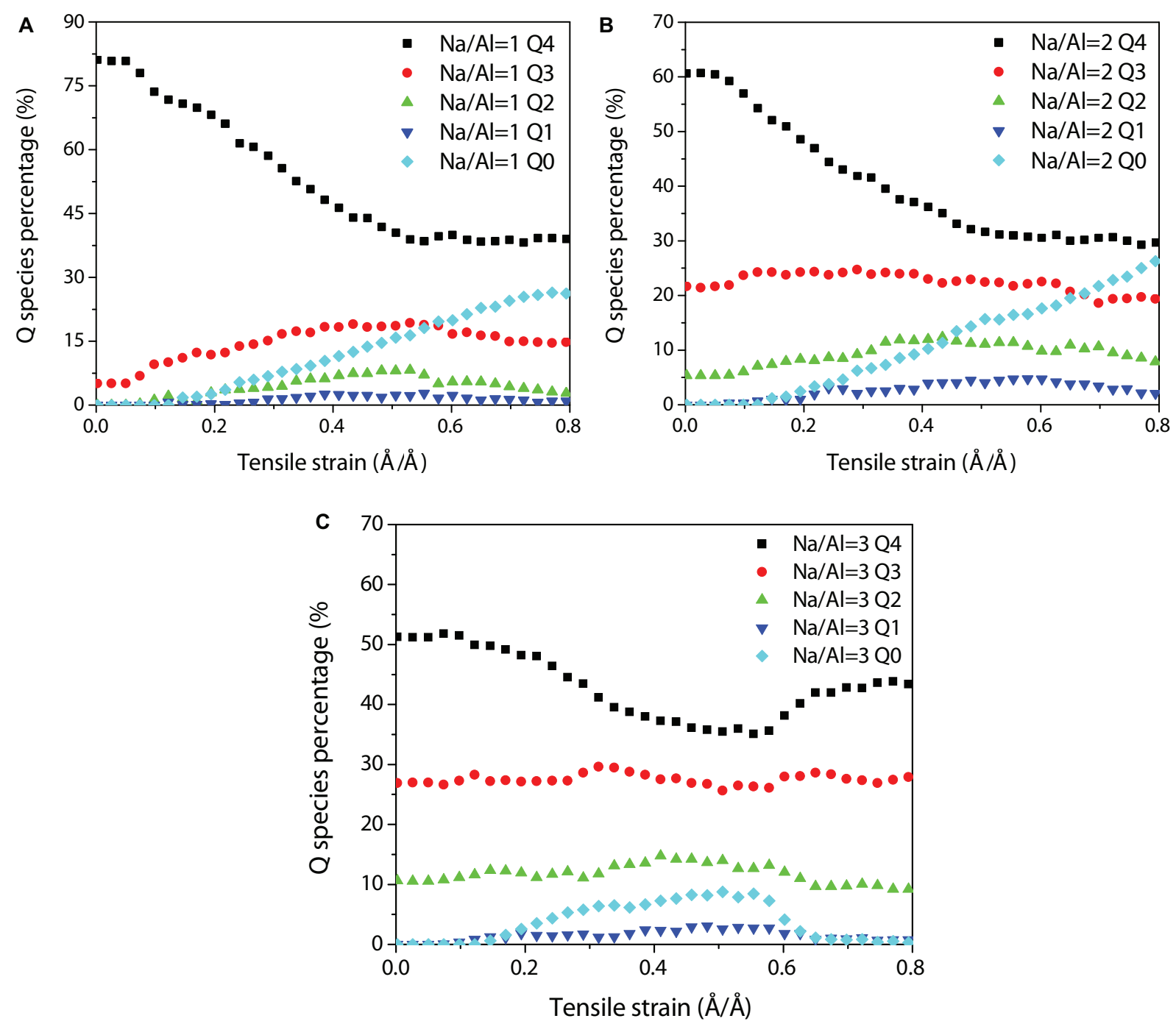

FIGURE 7 | Evolution of $\mathrm{Q}_{n}$ species ( $n=0,1,2,3$, and 4) for the NASH gel with a Na/Al ratio of (A) 1, (B) 2, and (C) 3 during the tensile process at a strain rate of 0.08 ps.

of the structure during the tensile process (Figure 5). In stage 2 (the failure region), the $\mathrm{Si}-\mathrm{O}$ distance observed in $\mathrm{RDF}$, recovered close to that of the unstrained state $(1.62 \AA)$. The trends of $\mathrm{RDF}$ for $\mathrm{Al}-\mathrm{O}$ are the same, and further verifies the evolution of structure during the tensile process.

A similar evolution trend can be obtained in the angle distribution variation as a function of the strain. As shown in Figure $6 \mathrm{C}$, the average value of the $\mathrm{Si}-\mathrm{O}-\mathrm{Si}$ angle is stretched from $139.2^{\circ}$ to $150.7^{\circ}$ in the elastic region. However, in the yield region, the angle remains basically unchanged and finally returns to the unstrained state. These are consistent with the trends of RDFs.

To depict the structural variation of the aluminosilicate skeleton, the change of $\mathrm{Q}_{\mathrm{n}}$ percentages has been calculated. $\mathrm{Q}$ species play an important role in the quantitative analysis of the morphological evolution. A connectivity factor, $\mathrm{Q}_{\mathrm{n}}(n=0,1,2$, 3 , and 4), is a parameter that estimates the molecular skeleton connection, where $n$ is the number of connected BO of central atoms ( $\mathrm{Si}$ or $\mathrm{Al}$ ). $\mathrm{Q}_{0}$ is the monomer; $\mathrm{Q}_{1}$ represents the dimmer structure (two connected BO of central atoms); $\mathrm{Q}_{2}$ is the long chain; $\mathrm{Q}_{3}$ is the branch structure; and $\mathrm{Q}_{4}$ is the network structure (Feuston and Garofalini, 1990). When the system reaches the thermodynamic equilibrium state, the basic parameters of the $\mathrm{Q}$ species, $\mathrm{BO}$, and $\mathrm{NBO}$ in different $\mathrm{Na} / \mathrm{Al}$ ratio samples are shown in Table 4. It is basically consistent with the experimental results (Sadat et al., 2016). With a $\mathrm{Na} / \mathrm{Al}$ ratio increase, the percentage of $\mathrm{Q}_{4}$ species (from 81.22 to $51.25 \%$ ) and BO are both decreased, implying that the network structure (aluminosilicate skeleton) depolymerizes, further resulting in a decrease of the mechanical properties. Furthermore, the aluminosilicate skeleton depolymerizes to branch structure, long chain, short chains, or monomers, so that the percentage of other phases, including $\mathrm{Q}_{3}$, $\mathrm{Q}_{2}$, and $\mathrm{Q} 1$ obviously increases as the sodium content increases.

During the tensile process, the $\mathrm{Q}$ species can depict the structural variation of the aluminosilicate skeleton quantitatively. 

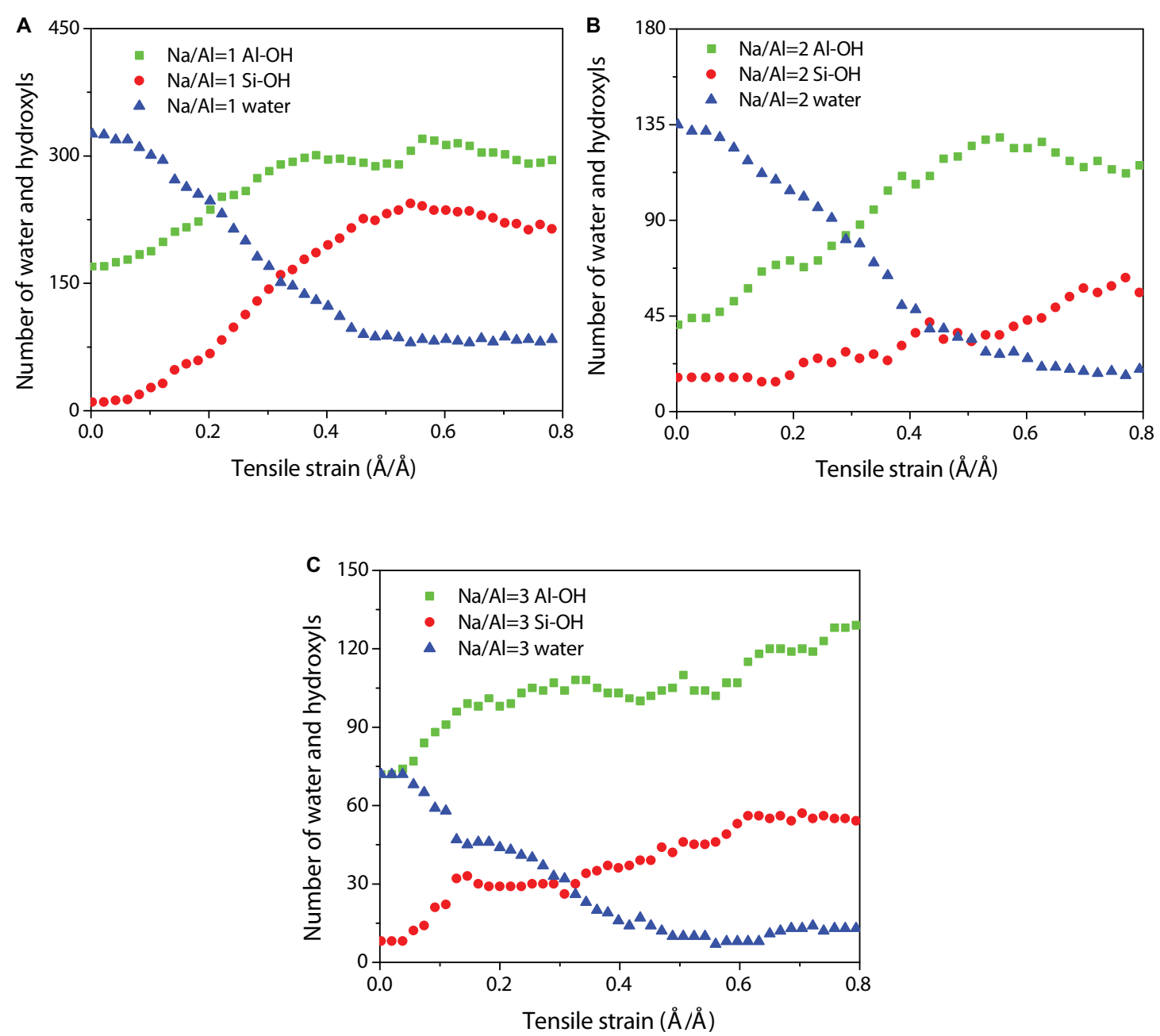

FIGURE 8 | Evolution of the number of water molecules and hydroxyl as functions of strain with a Na/Al ratio of (A) 1, (B) 2, and (C) 3.

At the beginning of the elastic stage, the aluminosilicate skeleton takes up the strain by changing the $\mathrm{Si}-\mathrm{O}$ and $\mathrm{Al}-\mathrm{O}$ bonds, and the $\mathrm{Q}_{4}$ percentage remains unchanged at low strain levels for the NASH gel with all $\mathrm{Na} / \mathrm{Al}$ ratios (Figure 7), implying

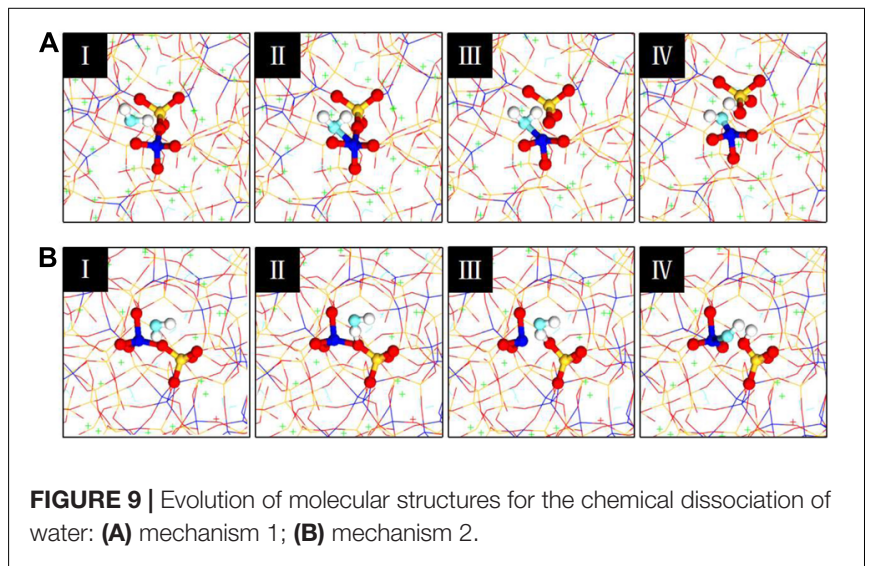

that the structure only undergoes elastic deformation with no structural damage. As the strain increases, the $\mathrm{Q}_{4}$ species starts to reduce at a strain of $0.06 \AA / \AA$ and continues to decrease from 81 to $39 \%$. This means that some aluminosilicate skeletons were stretched broken, resulting in the morphological transformation from network structure to branch structure, long chain, short chains, or monomers. At the failure stage, the $\mathrm{Q}_{4}$ species percentage decreases slightly and finally tends to become stable. Furthermore, the increase of the $\mathrm{Q}_{3}$ and $\mathrm{Q}_{2}$ species suggests that the network transforms to branch structures and long aluminosilicate chains. The $\mathrm{Q}_{3}$ and $\mathrm{Q}_{2}$ species continued to depolymerize to shorter chains and monomers, and the proportion of other $\mathrm{Q}$ species $\left(\mathrm{Q}_{1}, \mathrm{Q}_{0}\right)$ also increased later. The tensile damage of the NASH gel structures is therefore mainly attributed to the depolymerization of the aluminosilicate network. The $\mathrm{Q}_{4}$ species percentage increased partially in the NASH gel with a $\mathrm{Na} / \mathrm{Al}$ ratio of 3 at the failure stage, suggesting that the increase of sodium content rearranges the structure by electrostatic attraction of Coulomb force. 

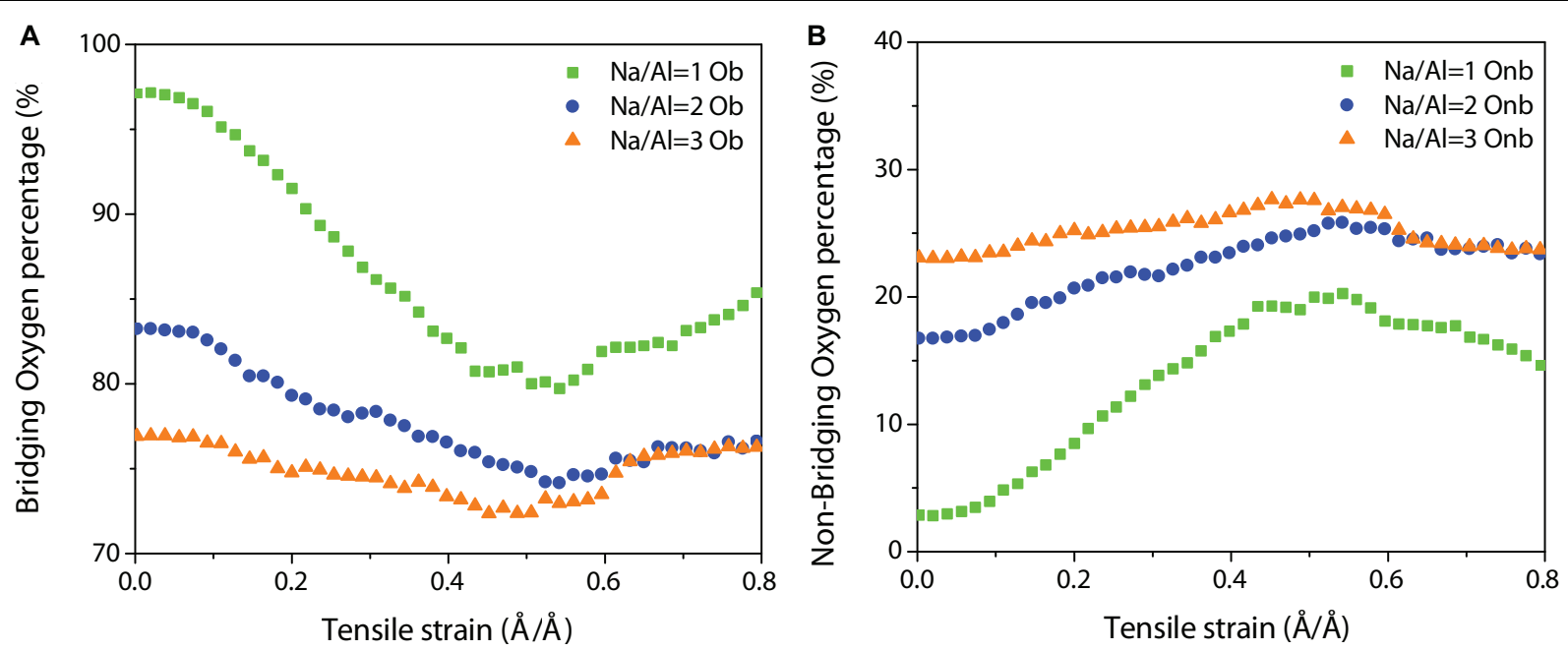

FIGURE 10 | Evolution of (A) bridging oxygen and (B) non-bridging oxygen as functions of strain.

\section{Hydrolytic Reaction Under Tensile Loading}

According to previous studies, water molecules play an important role in the depolymerization of the aluminosilicate network during the tensile process, and the chemical dissociations can be observed (Hou et al., 2014a, 2015c). Water molecules attack the $\mathrm{Si}-\mathrm{O}-\mathrm{Si}$ and $\mathrm{Si}-\mathrm{O}-\mathrm{Al}$ bonds form $\mathrm{Si}-\mathrm{OH}$ and $\mathrm{Al}-\mathrm{OH}$ groups, then further weakens the aluminosilicate skeleton during the tensile process. Therefore, the number of $\mathrm{Si}-\mathrm{OH}, \mathrm{Al}-\mathrm{OH}$ groups, and water molecules were recorded as functions of strain to analyze the dissociation process quantitatively. The primary factor of the tensile process is the chemical effect. For the sample with a $\mathrm{Na} / \mathrm{Al}$ ratio of 1 (Figure $\mathbf{8 A}$ ), the number of water molecules decreases as the strain increases until reaching a strain of $0.5 \AA / \AA$, and then it remains unchanged, implying that a large number of water molecules dissociate with the strain increase. The number of $\mathrm{Si}-\mathrm{OH}$ and $\mathrm{Al}-\mathrm{OH}$ groups increases co-instantaneous, and is close to a stable state at the strain of $0.5 \AA / \AA$. This indicates that the hydrolysis reaction has gradually occurred in large quantities, especially after the strain is greater than $0.05 \AA / \AA$. It is consistent with the theory that increasing the stress in the structure can reduce the energy barrier for activating the hydrolytic reaction (Zhu et al., 2005). For samples with different $\mathrm{Na} / \mathrm{Al}$ ratios, the strain at which the number of water molecules starts to reduce with a $\mathrm{Na} / \mathrm{Al}$ ratio increase (Figures $\mathbf{8 B}, \mathrm{C}$ ). In addition, at the same strain rate in the failure region, the number of water molecules of NASH gels with higher $\mathrm{Na} / \mathrm{Al}$ ratios are significantly smaller than that of the lower sample. These are good validations of the inference that increasing the amount of sodium content accelerates the hydrolytic reaction and the silicate structure transformation, which can be interpreted by the attack on $\mathrm{Si}-\mathrm{O}$ and $\mathrm{Al}-\mathrm{O}$ bonds from sodium ions. Furthermore, the number of Al-OH groups increases significantly more than that of $\mathrm{Si}-\mathrm{OH}$ as the $\mathrm{Na} / \mathrm{Al}$ ratio increases. This is related to the poorer stability of Al-O bonds than Si-O bonds.

The hydrolytic reaction greatly affects the silicate structure transformation during the uniaxial tension process. The reaction mechanisms of water dissociation have been investigated, and there are two reaction mechanisms: the first mechanism of reaction started in the yield stage and is listed in the following sequence (Figure 9A): water diffuses and water molecule is adsorbed close to the neighboring aluminum atom; a bond forms between the aluminum atom and the oxygen atom of the water molecule; a five coordination aluminum structure is formed; the Al-O bond is broken and the aluminum structure restores to four coordination; the water molecule dissociation and proton transfers. In the dissociation process, water molecules lead to the formation of a five coordination aluminum structure, which is disadvantageous in terms of energy. Then the unstable structure separates from the BO. The stretched $\mathrm{Si}-\mathrm{O}-\mathrm{Al}$ bond was attacked by water molecules, and the separation of aluminosilicate network was accelerated. The other mechanism of water dissociation is illustrated in Figure 9B, the aluminosilicate skeleton was stretched broken by increasing the tensile strain. The sequence is displayed as follows: the water molecule diffuses close to the neighboring $\mathrm{Si}-\mathrm{O}-\mathrm{Al}$ bond or Si$\mathrm{O}-\mathrm{Si}$ bond; a bond is formed between the $\mathrm{BO}$ atom and the hydrogen atom of water molecules; the Al-O bond or Si-O bond is broken; water dissociation and proton transfers. However, it should be noted that Al-O bonds are more unstable and easily broken than $\mathrm{Si}-\mathrm{O}$ bonds.

On the other hand, the dissociation process of water corresponds to the evolution of $\mathrm{BO}$ (Figure 10A) and NBO (Figure 10B) as functions of strain. During the tensile process, the percentage of $\mathrm{BO}$ decreases, and that of $\mathrm{NBO}$ increases as the $\mathrm{Na} / \mathrm{Al}$ ratio increases from 1 to 3 . It means that the aluminosilicate networks with a lower $\mathrm{Na} / \mathrm{Al}$ ratios have a higher degree of polymerization, confirming the previous conclusion that an increase of sodium content leads to a decrease in the degree of polymerization and in the mechanical strength of system.

With an increase in the strain, the percentage change of $\mathrm{BO}$ and NBO shows nearly the opposite tendencies. At the beginning 
of the elastic region, the percentage of $\mathrm{BO}$ and $\mathrm{NBO}$ is relatively stable, that is the process of crossing the energy barrier for activating the hydrolytic reaction (Hou et al., 2019c). And then the percentage of $\mathrm{BO}$ drops sharply and the percentage of NBO increases up to the tensile strain of around $0.4 \AA / \AA$. With an increase of tensile strain before failure, the percentage of $\mathrm{BO}$ reduces slowly and fluctuates on a small-scale, which can also be found in the opposite trend of change for NBO. This is consistent with the analysis of the hydrolysis mechanism above. Thus, the hydrolytic reaction of water molecules near the stretched $\mathrm{Si}-\mathrm{O}$ and $\mathrm{Al}-\mathrm{O}$ bond further accelerates the NASH gel degradation to resist the tensile loading.

\section{CONCLUSION}

Based on the molecular dynamics by a ReaxFF, the structure, reactivity, and mechanical performance of the NASH gel with a $\mathrm{Na} / \mathrm{Al}$ ratio ranging from 1 to 3 have been investigated. The conclusions can be drawn as follows.

(1) For NASH gels with different $\mathrm{Na} / \mathrm{Al}$ ratios, $\mathrm{Si}$ and $\mathrm{Al}$ are predominantly tetrahedral, and the tetrahedral $\mathrm{SiO}_{4}$ structure and silicate skeleton are not sensitive to the $\mathrm{Na} / \mathrm{Al}$ ratio. The sodium ions distributed in the NASH gel have around $4 \sim 7$ nearest neighbors including oxygen atoms in the silicate/aluminate tetrahedron and hydroxyl. The adsorbed water molecules dissociate into the hydroxyl group near the defective aluminosilicate structure, contributing to the formation of an aluminate pentahedron.

(2) With the amount of sodium content increasing, the molecular structure of the aluminosilicate skeleton transforms from an integrity network to partially destroyed branch structures, decreasing the strength and cohesive force of the $\mathrm{NASH}$ gel, characterized by the uniaxial tensile testing. It means that the connection of the aluminosilicate skeleton becomes unstable and further affects the tensile properties of the structure, due to the attack on the Si-O-Si and Si-O-Al bond by sodium ions.

\section{REFERENCES}

Andrew, R. M. (2018). Global CO2 emissions from cement production. Earth Syst. Sci. Data 10, 195-217. doi: 10.5194/essd-10-1952018

Bakharev, T. (2005). Geopolymeric materials prepared using Class F fly ash and elevated temperature curing. Cem. Concr. Res. 35, 1224-1232. doi: 10.1016/j. cemconres.2004.06.031

Barbosa, V. F., and MacKenzie, K. J. (2003). Thermal behaviour of inorganic geopolymers and composites derived from sodium polysialate. Mater. Res. Bull. 38, 319-331. doi: 10.1016/s0025-5408(02)01022-x

Barbosa, V. F. F., Mackenzie, K. J. D., and Thaumaturgo, C. (2000). Synthesis and characterisation of materials based on inorganic polymers of alumina and silica: sodium polysialate polymers. Int. J. Inorg. Mater. 2, 309-317. doi: 10.1016/ s1466-6049(00)00041-6

Bonnaud, P., Ji, Q., Coasne, B., Pellenq, R.-M., and Van Vliet, K. (2012). Thermodynamics of water confined in porous calcium-silicate-hydrates. Langmuir 28, 11422-11432. doi: 10.1021/la301738p
(3) The aluminosilicate skeleton is stretched broken to resist the tensile loading. A high degree of polymerization of the aluminosilicate skeleton network enhances the loading resistance. As the $\mathrm{Na} / \mathrm{Al}$ ratio increases, the polymerization degree of the aluminosilicate skeleton gradually decreases, and the defective aluminosilicate chains produce more NBO.

(4) Water molecules play an important role in the depolymerization of the aluminosilicate network during the tensile process, and the chemical dissociations can be observed. The adsorption and dissociation are promoted by hydrophilic $\mathrm{NBO}$, further forming $\mathrm{Si}-\mathrm{OH}$ and $\mathrm{Al}-\mathrm{OH}$ with the surrounding aluminosilicate skeleton. And the number of $\mathrm{Al}-\mathrm{OH}$ changes more than that of $\mathrm{Si}-\mathrm{OH}$ at high $\mathrm{Na} / \mathrm{Al}$ ratios due to the increase of the sodium content.

\section{DATA AVAILABILITY STATEMENT}

All datasets generated for this study are included in the article/supplementary material.

\section{AUTHOR CONTRIBUTIONS}

ZL, JZ, and MW are the primary contributors in this work, performed this work, and reviewed the manuscript and approved it for publication.

\section{FUNDING}

Funding support for this study was provided by the National Natural Science Foundation of China (Grant Nos. 51678317, 51420105015, and 51909147), the China Ministry of Science and Technology (Grant No. 2015CB655100), the Natural Science Foundation of Shandong Province (Grant Nos. ZR2017JL024 and ZR2019MEM041), and The Fok Ying-Tong Education Foundation for Young Teachers in the Higher Education Institutions of China (Grant No. 161069).

Brenner, D. W., Shenderova, O. A., Harrison, J. A., Stuart, S. J., Ni, B., and Sinnott, S. B. (2002). A second-generation reactive empirical bond order (REBO) potential energy expression for hydrocarbons. J. Phys. Condens. Matter 14, 783-802. doi: 10.1088/0953-8984/14/4/312

Cygan, R. T., Liang, J.-J., and Kalinichev, A. G. (2004). Molecular models of hydroxide, oxyhydroxide, and clay phases and the development of a general force field. J. Phys. Chem. B 108, 1255-1266. doi: 10.1021/jp036 3287

Damtoft, J. S., Lukasik, J., Herfort, D., Sorrentino, D., and Gartner, E. M. (2008). Sustainable development and climate change initiatives. Cem. Concr. Res. 38, $115-127$.

Davidovits, J. (1982). Mineral Polymers and Methods of Making Them. US Patent No 44721993.

Davidovits, J. (1991). Geopolymers. J. Therm. Anal. Calorim. 37, 16331656.

De Silva, P., Sagoe-Crenstil, K., and Sirivivatnanon, V. (2007). Kinetics of geopolymerization: role of $\mathrm{Al} 2 \mathrm{O} 3$ and $\mathrm{SiO} 2$. Cem. Concr. Res. 37, 512-518. doi: 10.1016/j.cemconres.2007.01.003 
Duin, A. C. T. V., Dasgupta, S., Lorant, F., and Goddard, W. A. (2001). ReaxFF: a reactive force field for hydrocarbon. J. Phys. Chem. A 105, 9396-9409.

Duxson, P., Fernández-Jiménez, A., Provis, J. L., Lukey, G. C., Palomo, A., and Deventer, J. S. J. V. (2007a). Geopolymer technology: the current state of the art. J. Mater. Sci. 42, 2917-2933. doi: 10.1007/s10853-006-0637-z

Duxson, P., Lukey, G. C., Separovic, F., and van Deventer, J. S. (2005). Effect of alkali cations on aluminum incorporation in geopolymeric gels. Ind. Eng. Chem. Res 44, 832-839. doi: 10.1021/ie0494216

Duxson, P., Provis, J. L., Lukey, G. C., and Deventer, J. S. J. V. (2007b). The role of inorganic polymer technology in the development of 'green concrete'. Cem. Concr. Res. 37, 1590-1597. doi: 10.1016/j.cemconres.2007.08.018

Duxson, P., Provis, J. L., Lukey, G. C., Mallicoat, S. W., Kriven, W. M., and van Deventer, J. S. (2005a). Understanding the relationship between geopolymer composition, microstructure and mechanical properties. Colloids Surf. A Physicochem. Eng. Aspect 269, 47-58. doi: 10.1016/j.colsurfa.2005. 06.060

Duxson, P., Provis, J. L., Lukey, G. C., Separovic, F., and van Deventer, J. S. (2005b). 29Si NMR study of structural ordering in aluminosilicate geopolymer gels. Langmuir 21, 3028-3036. doi: 10.1021/la047336x

Feuston, B., and Garofalini, S. (1990). Oligomerization in silica sols. J. Phys. Chem. 94, 5351-5356. doi: 10.1016/j.jcis.2011.01.064

Hou, D., Li, D., Zhao, T., and Li, Z. (2016a). Confined water dissociation in disordered silicates nanometer-channels at elevated temperatures: mechanism, dynamics and impact on the substrates. Langmuir 32, 4153-4168. doi: 10.1021/ acs.langmuir.6b00444

Hou, D., Li, Z., and Zhao, T. (2015a). Reactive force field simulation on polymerization and hydrolytic reactions in calcium aluminate silicate hydrate (C-A-S-H) gel: structure, dynamics and mechanical properties. Rsc Adv. 5, 448-461. doi: 10.1039/c4ra10645h

Hou, D., Lu, Z., Zhao, T., and Ding, Q. (2016b). Reactive molecular simulation on the ordered crystal and disordered glass of the calcium silicate hydrate gel. Ceram. Int. 42, 4333-4346. doi: 10.1016/j.ceramint.2015.11.112

Hou, D., Ma, H., Li, Z., and Jin, Z. (2014a). Molecular simulation of "hydrolytic weakening": a case study on silica. Acta Mater. 80, 264-277. doi: 10.1016/j. actamat.2014.07.059

Hou, D., Yu, J., and Wang, P. (2019a). Molecular dynamics modeling of the structure, dynamics, energetics and mechanical properties of cement-polymer nanocomposite. Compos. Part B Eng. 162, 433-444. doi: 10.1016/j.compositesb. 2018.12.142

Hou, D., Zhang, J., Li, Z., and Zhu, Y. (2015b). Uniaxial tension study of calcium silicate hydrate $(\mathrm{C}-\mathrm{S}-\mathrm{H})$ : structure, dynamics and mechanical properties. Mater. Struct. 48, 3811-3824. doi: 10.1617/s11527-014-0441-1

Hou, D., Zhang, J., Pan, W., Zhang, Y., and Zhang, Z. (2019b). Nanoscale mechanism of ions immobilized by the geopolymer: a molecular dynamics study. J. Nuclear Mater. 528:151841. doi: 10.1016/j.jnucmat.2019.15 1841

Hou, D., Zhang, Q., Xu, X., Zhang, J., Li, W., and Wang, P. (2019c). Insights on ions migration in the nanometer channel of calcium silicate hydrate under external electric field. Electrochim. Acta 320, 134637. doi: 10.1016/j.electacta. 2019.134637

Hou, D., Zhao, T., Ma, H., and Li, Z. (2015c). Reactive molecular simulation on water confined in the nanopores of the calcium silicate hydrate gel: structure, reactivity, and mechanical properties. J. Phys. Chem. C 119, 1346-1358. doi: $10.1021 /$ jp509292q

Hou, D., Zhao, T., Wang, P., Li, Z., and Zhang, J. (2014b). Molecular dynamics study on the mode I fracture of calcium silicate hydrate under tensile loading. Eng. Fract. Mech. 131, 557-569. doi: 10.1016/j.engfracmech.2014. 09.011

Irwin, A. D., Holmgren, J. S., and Jonas, J. (1988). $27 \mathrm{Al}$ and 29 Si NMR study of sol-gel derived aluminosilicates and sodium aluminosilicates. J. Mater. Sci. 23, 2908-2912. doi: 10.1007/bf00547467

Kriven, W. M., Bell, J. L., and Gordon, M. (2003). Microstructure and microchemistry of fully-reacted geopolymers and geopolymer matrix composites. Ceram. Trans. 153, 227-250. doi: 10.1002/9781118406892. ch15

Leonelli, C., Lusvardi, G., Montorsi, M., Menziani, M. C., Menabue, L., Mustarelli, P., et al. (2001). Influence of small additions of $\mathrm{Al} 2 \mathrm{O} 3$ on the properties of the $\mathrm{Na} 2 \mathrm{O} \odot 3 \mathrm{SiO} 2$ Glass. J. Phys. Chem. B 105, 919-927.
Li, Z. (2011). Advanced Concrete Technology. Hoboken, NJ: John Wiley \& Sons. Luukkonen, T., Abdollahnejad, Z. Yliniemi, J., Kinnunen, P., and Illikainen, M. (2018). One-part alkali-activated materials: a review. Cem. Concr. Res. 103, 21-34.

Mauri, F., Pasquarello, A., Pfrommer, B. G., Yoon, Y.-G., and Louie, S. G. (2000). SiO-Si bond-angle distribution in vitreous silica from first-principles $29 \mathrm{Si}$ NMR analysis. Phys. Rev. B 62:R4786.

McKeown, D., Galeener, F., and Brown, G. Jr. (1984). Raman studies of Al coordination in silica-rich sodium aluminosilicate glasses and some related minerals. J. Non Crystall. Solids 68, 361-378. doi: 10.1016/0022-3093(84) 90017-6

Mozzi, R., and Warren, B. (1969). The structure of vitreous silica. J. Appl. Crystallogr. 2, 164-172.

Okuno, M., Zotov, N., Schmücker, M., and Schneider, H. (2005). Structure of SiO2-Al2O3 glasses: combined X-ray diffraction, IR and Raman studies. J. Non Crystall. Solids 351, 1032-1038. doi: 10.1016/j.jnoncrysol.2005.01.014

Palomo, A., and Glasser, F. (1992). Chemically-bonded cementitious materials based on metakaolin. Br. Ceram. Trans. J. 91, 107-112. doi: 10.3390/ ma12030442

Palomo, A., Grutzeck, M., and Blanco, M. (1999). Alkali-activated fly ashes: a cement for the future. Cem. Concr. Res. 29, 1323-1329. doi: 10.1016/s00088846(98)00243-9

Parthasarathy, P., Hanif, A., Shao, H., and Li, Z. (2017). "Microstructural and morphological studies of ordinary portland cement paste and fly ash based geopolymer in the presence of chloride ions," in Proceedings of the 71st RILEM Week and ICACMS 2017 - International Conference on Advances in Construction Materials and Systems, Chennai, 623.

Rowles, M., and O'connor, B. (2003). Chemical optimisation of the compressive strength of aluminosilicate geopolymers synthesised by sodium silicate activation of metakaolinite. J. Mater. Chem. 13, 1161-1165. doi: 10.1039/ b212629j

Sadat, M. R., Bringuier, S., Asaduzzaman, A., Muralidharan, K., and Zhang, L. (2016). A molecular dynamics study of the role of molecular water on the structure and mechanics of amorphous geopolymer binders. J. Chem. Phys. 145:134706. doi: 10.1063/1.4964301

Schmücker, M., and MacKenzie, K. J. (2005). Microstructure of sodium polysialate siloxo geopolymer. Ceram. Int. 31, 433-437. doi: 10.1016/j.ceramint.2004. 06.006

Singh, P. S., Trigg, M., Burgar, I., and Bastow, T. (2005). Geopolymer formation processes at room temperature studied by $29 \mathrm{Si}$ and $27 \mathrm{Al}$ MAS-NMR. Mater. Sci. Eng. A 396, 392-402. doi: 10.1016/j.msea.2005. 02.002

Uchino, T., Sakka, T., Ogata, Y., and Iwasaki, M. (1993). Local structure of sodium aluminosilicate glass: an ab initio molecular orbital study. J. Phys. Chem. 97, 9642-9649. doi: 10.1021/j100140a019

Van Jaarsveld, J., Van Deventer, J., and Lukey, G. (2002). The effect of composition and temperature on the properties of fly ash-and kaolinitebased geopolymers. Chem. Eng. J. 89, 63-73. doi: 10.1016/s1385-8947(02)0 0025-6

Walkley, B., Rees, G. J., San Nicolas, R., van Deventer, J. S., Hanna, J. V., and Provis, J. L. (2018). New structural model of hydrous sodium aluminosilicate gels and the role of charge-balancing extra-framework Al. J. Phys. Chem. C 122, 5673-5685. doi: 10.1021/acs.jpcc.8b00259

Wang, P., Zhang, Q., Wang, M., Yin, B., Hou, D., and Zhang, Y. (2019). Atomistic insights into cesium chloride solution transport through the ultra-confined calcium-silicate-hydrate channel. Phys. Chem. Chem. Phys. 21, 11892-11902. doi: $10.1039 / \mathrm{c} 8 \mathrm{cp} 07676 \mathrm{f}$

White, C. E., Provis, J. L., Proffen, T., and van Deventer, J. S. (2012). Molecular mechanisms responsible for the structural changes occurring during geopolymerization: multiscale simulation. AICHE J. 58, 2241-2253. doi: 10 . $1002 /$ aic. 12743

Xiang, Y., Du, J., Smedskjaer, M. M., and Mauro, J. C. (2013). Structure and properties of sodium aluminosilicate glasses from molecular dynamics simulations. J. Chem. Phys. 139:044507. doi: 10.1063/1.48 16378

Xu, H., and Van Deventer, J. (2000). The geopolymerisation of alumino-silicate minerals. Int. J. Miner. Process. 59, 247-266. doi: 10.1016/s0301-7516(99) 00074-5 
Zhang, M., Deskins, N. A., Zhang, G., Cygan, R. T., and Tao, M. (2018). Modeling the polymerization process for geopolymer synthesis through reactive molecular dynamics simulations. J. Phys. Chem. C 122, 6760-6773. doi: 10. 1021/acs.jpcc.8b00697

Zhang, Y., Zhang, J., Jiang, J., Hou, D., and Zhang, J. (2018). The effect of water molecules on the structure, dynamics, and mechanical properties of sodium aluminosilicate hydrate (NASH) gel: a molecular dynamics study. Constr. Build. Mater. 193, 491-500. doi: 10.1016/j.conbuildmat.2018.10.221

Zhu, T., Li, J., Lin, X., and Yip, S. (2005). Stress-dependent molecular pathways of silica-water reaction. J. Mech. Phys. Solids 53, 1597-1623. doi: 10.1016/j.jmps. 2005.02.002
Conflict of Interest: The authors declare that the research was conducted in the absence of any commercial or financial relationships that could be construed as a potential conflict of interest.

Copyright (C) $2020 \mathrm{Li}$, Zhang and Wang. This is an open-access article distributed under the terms of the Creative Commons Attribution License (CC BY). The use, distribution or reproduction in other forums is permitted, provided the original author(s) and the copyright owner(s) are credited and that the original publication in this journal is cited, in accordance with accepted academic practice. No use, distribution or reproduction is permitted which does not comply with these terms. 